\title{
Evidence-based design of perceived pathways in cold regional parks for elderly health behaviour
}

Tianjiao YAN, School of Architecture, Harbin Institute of Technology; Key Laboratory of Cold Region Urban and Rural Human Settlements Environment Science and Technology, Ministry of Industry and Information and Technology, China

Hong LENG, School of Architecture, Harbin Institute of Technology; Key Laboratory of Cold Region Urban and Rural Human Settlements Environment Science and Technology, Ministry of Industry and Information and Technology, China

\begin{abstract}
The aging situation of China is severe at this stage. There is no doubt about the utility of parks to physical and mental health of the elderly, and it is also an important space carrier for elderly health behaviour. Among them, paths are the most used space by the elderly, and it is necessary to explore the coupling results of the senior internal requirements and the evaluation of the perceived environment. This study focused on cold regions, with the elderly as the main body of investigation, and park pathways as the spatial object, in order to explore: 1 ) healthy behaviour patterns on pathways in different times and seasons; 2 ) perceived environmental characteristics that significantly affect the occurrence of elderly health behaviours; 3 ) perceived evaluation of elderly people on pathways with different characteristics. The results show that in winter park pathways, healthy behaviours are dominated by dynamic behaviours for fitness purpose. The factors that have the greatest impact on the development of healthy behaviours are route design and the accessibility of activity area, and the sense of security is the main concern. In nonwinter path space, there are more static behaviours for recreational purpose. Route design, scale, plants and accessibility of water are the most influential spatial elements, and the most important requirement is comfort and scenic beauty. In addition, comparing the use of pathways during daytime and nighttime, the biggest needs at night are good lighting conditions and smooth paving. Finally, based on the above discussion and scoring evaluation results, we tried to provide targeted and implementable suggestions and measures for the optimization of pathways in similar cold regional parks.
\end{abstract}

\section{Keywords}

Evidence-based design, Pathways, Cold regional parks, Elderly health behaviour

\section{Introduction}

According to the data of the National Bureau of statistics, by the end of 2019, the population over the age of 60 in China had reached 253.88 million, accounting for $18.1 \%$ of the total population. It is expected that the proportion will increase to $28 \%$ in 2040 . The national "14th five year plan" proposes to raise the response to aging as a national strategy. Simultaneously, according to the 2012 World Health Organization global disease burden assessment report, $45 \%$ of the disability adjusted life years (DALYs) in China are caused by the health problems of the elderly aged 60 and over. The main health problems that cause the disease burden of the elderly in China include: cardiovascular and cerebrovascular diseases, respiratory 
diseases, diabetes, mental health problems and falls. It can be seen that the domestic aging and elderly health situation is not optimistic, and how to respond positively has long become the focus of social attention. At present, the aging structure in China is characterized by a large proportion of young elderly (less than 70 years old). This kind of population is also the main body of health behaviour outdoors. Therefore, it is of great significance to promote the outdoor health behaviour of the elderly as the pointcut of active aging.

The outdoor health behaviour of the elderly refers to all health promoting physical activities outdoors. Its rehabilitation benefits include the dual benefits of physical activities and natural environment to the elderly. The World Health Organization defines physical activity as the energy consumption caused by any skeletal muscle exercise outdoors, including walking, cycling, aerobic exercise, etc., which has outstanding benefits for the physical rehabilitation and health improvement of the elderly (Tinsley, H.E.A. etc..2002). In addition, the rehabilitation benefits of natural environment for the elderly are far greater than those of medicine. Modern convalescence medicine confirms that the natural environment is an important element to promote the physical and mental health of the elderly (Danya, K., Jin, J..2018), and various landscapes in parks have positive effects on the physical and mental health of the elderly (Kemperman, A.D.A.M., Timmermans, H.J.P.2006).

Meanwhile, due to the long winter and cold climate in Northeast China, such climate conditions have increased obstacles to the daily winter fitness of the elderly to a certain extent. However, relevant studies have shown that the park environment, as an important carrier to encourage the elderly to carry out healthy behaviour, even if appropriate and regular fitness activities are carried out in winter, it can improve the body function, delay organ aging, enhance the functions of cardiovascular, cerebrovascular, nervous, digestive, muscle, bone and other system organs (Loukaitou-sideris, A. etc..2017\& Lee, I. etc.. 2012), so as to reduce the incidence and mortality of chronic diseases. Furthermore, some studies have found that forest recreation in winter is still good for mental health (Tucker, P., Gilliland, J..2017\&Leng, H.2009), which can reduce the generation of stress and emotional problems to a certain extent, and then effectively prevent and reduce the occurrence of mild cognitive impairment and seasonal affective disorder. Therefore, paying attention to the health behaviour of the elderly, attaching importance to its scientific rationality in winter, and improving the park environment according to the seasonal characteristics are important ways and development issues to promote national health and reduce the burden of social pension.

Currently, the relevant studies on the use of parks by the elderly are mostly combined with questionnaires, interviews, literature review and model construction (Shores, K. A., West, S. T..2008, Chungdo, J.J. etc..2011, \& Tester, J., Baker, R.2009), to analysis the environmental preference and post use evaluation (Hino, A. etc..2010, Han, B. etc..2013, \& Zhai, Y. etc..2020). Questionnaire survey and interview are undoubtedly the most convenient ways, but the results are usually seriously affected by the subjective feelings of participants. As a social research method, behavior observation does not need to interfere with the activities of the elderly, and it is not easy to be affected by their subjective cognition. It has the advantage of truly reflecting the environmental preferences and behaviour characteristics of the elderly. Although recent research have paid more attention to the behaviour patterns of the elderly in parks, there is few indepth studies on the health behaviour of the elderly in parks under the cold climate. Therefore, taking Changchun as an example, combined with behaviour observation, interview, map marking and statistical methods, this paper explored the relationship between paths and the elderly health behaviour in different seasons, which provided some reference for the paths design to promote active aging under the background of special regional climate. 


\section{Materials and methods}

\subsection{Data acquisition}

At present, the number of elderly people over 60 years old in Changchun has reached 1.9 million, accounting for $22 \%$ of the total. There are 90 urban parks in Changchun that can carry the health behaviour of the elderly, mainly distributed in the central area. The automobile industry development zone, with its high density of elderly population and insufficient park accessibility, is one of the breakthrough points for Changchun to effectively deal with aging. In this study, November 20-December 13, 2020 and May 6-May 12,2021 were selected as the investigation periods. The average temperature were about $-11^{\circ} \mathrm{C}$ and $10^{\circ} \mathrm{C}$ respectively, which had the universal characteristics of winter and spring climate. Considering that the elderly generally choose parks near their residential areas, excluding parks with too large or too small scale, we finally selected Daishan Park, Jinjiang Park, Changchun park and Jinxiu Park with more elderly people as the observation objects (they are simplified as DS Park, JJ Park, CC Park and JX Park respectively below).

Table 1. Excerpts from the atlas of pathways in sample parks

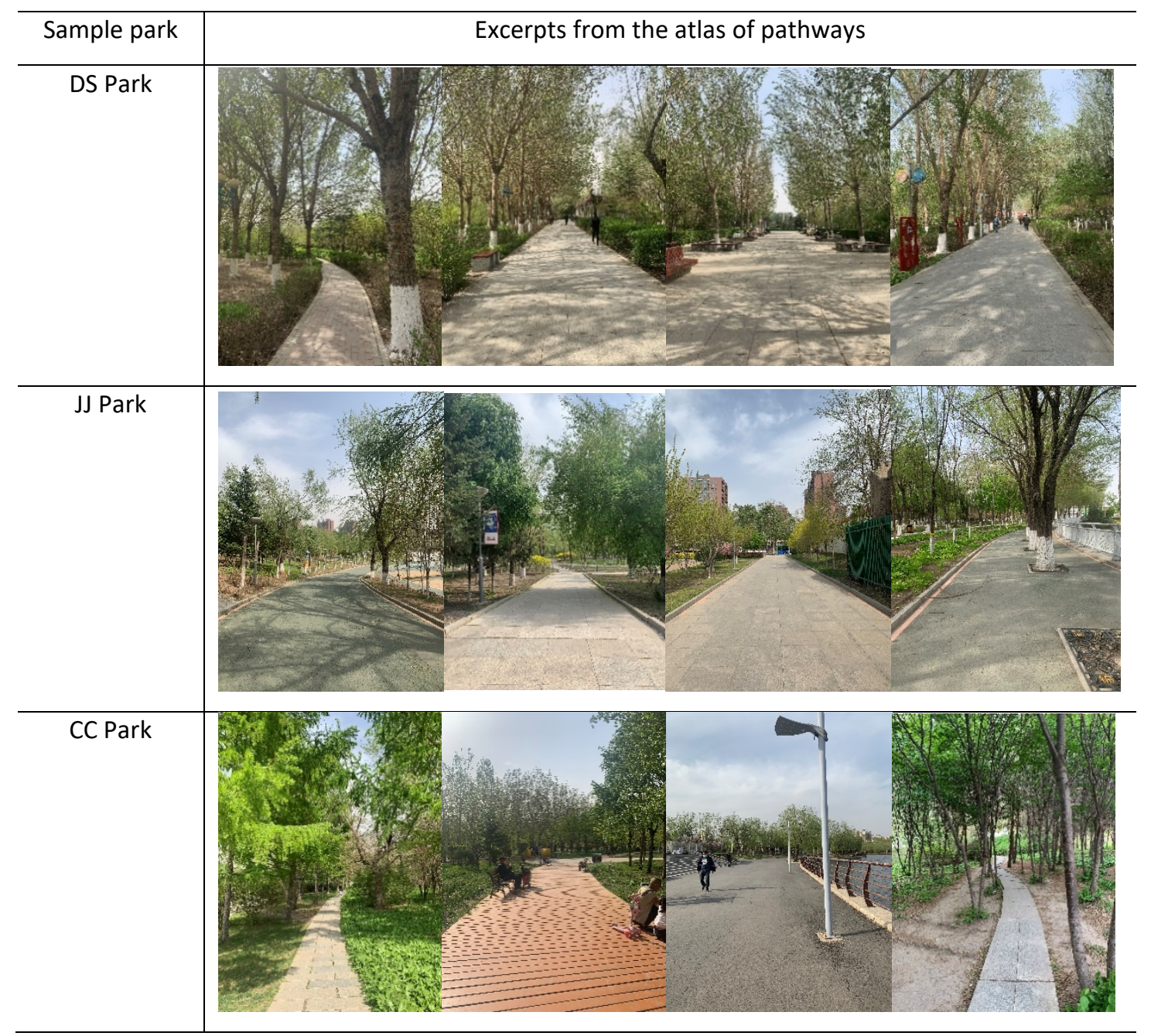


JX Park

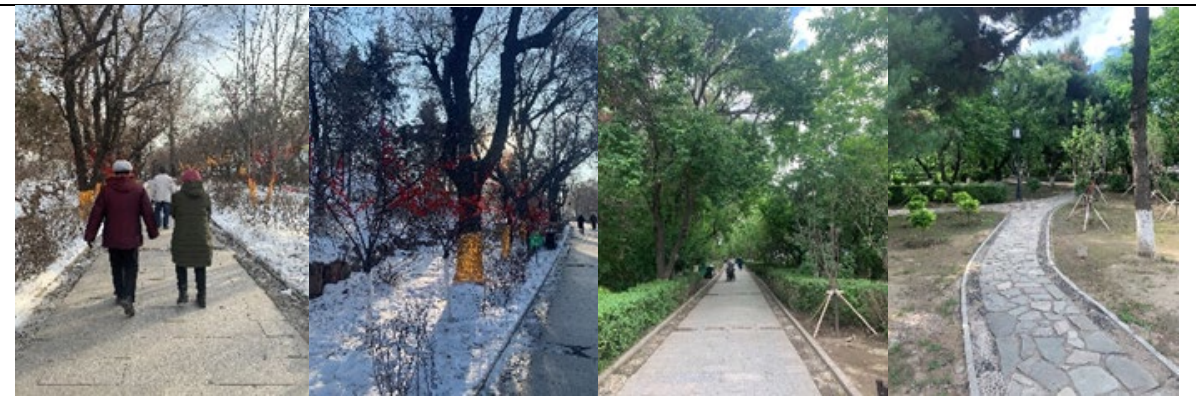

\subsection{Research design}

Firstly, through behaviour observation and map marking, we observed the behaviour types, number of activities and exercise intensity of the elderly in each time period of sample parks. We observed and recorded every time with a fixed route, stayed at each node for $10 \mathrm{~min}$, and selected the visual height of most elderly people $-1.6 \mathrm{~m}$ to take photos. By combining on-site records with rapid photo records, we formed a sample park pathways atlas (Table 1 ) and behaviour map to obtain the healthy behaviour law carried by these spaces. Then, we combined the regular and repeated interviews with 26 elderly users to mine their psychological perceived environmental needs according to word frequency. Afterwards, the above research results as the basis, through Excel and SPSS analysis, we explored the spatial characteristic elements that significantly impact on the health behaviour of the elderly, and constructed a fivedimensional evaluation standard to analysis the current situation. Finally, we tried to put forward optimization strategies of similar pathways in cold regional parks (Figure 1).
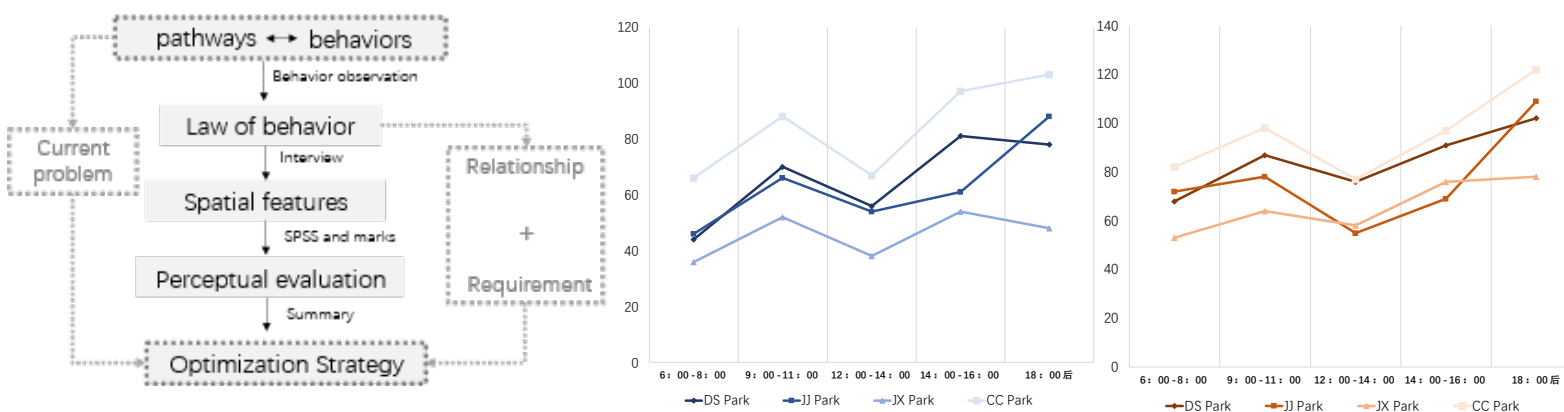

Figure 1. Research framework. Source: Authors. Figure 2. The number of the elderly on pathways in

different periods of winter and spring. Source: Authors.

\section{Results}

\subsection{Spatial and temporal distribution of health behaviour of the elderly carried by}

\section{pathways}

Elderly health behaviour carried by paths include walking and running fitness behaviours of individuals and 2-3 people groups, and leisure behaviours such as chatting, taking photos, walking dogs and so on. The number of visitors and exercise intensity are important indicators to characterize the spatial preference of elderly health behaviour. In winter, health behaviour of the elderly are mainly for the purpose of fitness, while in spring, the purpose of recreation are increasing. From the distribution of the number of people in a day, in winter the number of walking and running activities on pathways of DS and JX Park in daytime is higher than evening, and the peak value in JJ and CC Park is in the evening (Figure 2). In four sample parks in spring, the number of people at night is higher than that during the day (Figure 2). According to the 
overall presentation of the behaviour map, it can be found that there are significant differences in the number of activities between the main paths and internal paths in these parks (Figure 3 and 4).

According to the health standards of the World Health Organization, that is, the fast walking frequency $\geqslant$ 100 steps / min and the running frequency $\geqslant 150$ steps / min, we distinguished and recorded behaviours of different exercise intensity. MET can be understood as the energy consumption level relative to the resting metabolic state in a specific active state, and can be used to express the exercise intensity, formulate individualized exercise prescription, determine the maximum exercise ability and cardiac function level, etc. The MET value of mild exercise is less than 3, $3 \sim 6$ is moderate physical activity, and more than 6 is high-intensity exercise. We took the proportion of people with medium and high exercise intensity as the index, that is, the proportion of people with MET higher than 3 , to characterize the ability of path space to support activities with medium and high intensity. On this basis, we visualized the supportability of path space for different behaviours in sample parks (Figure 5 and 6), which is convenient for us to explore the law of elderly health behaviour carried by path spaces.

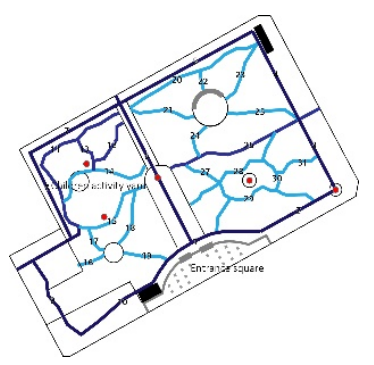

DS Park

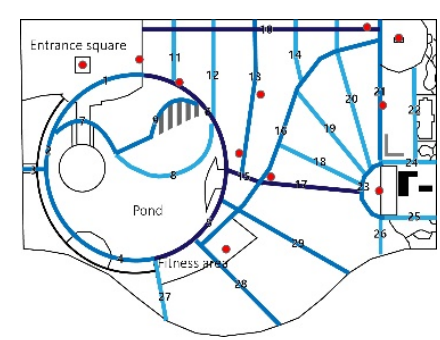

JJ Park

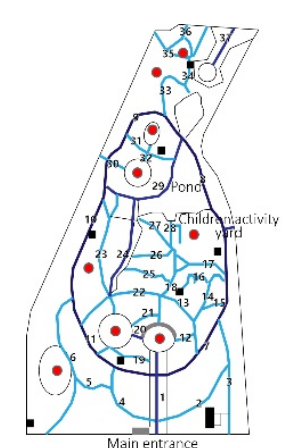

CC Park

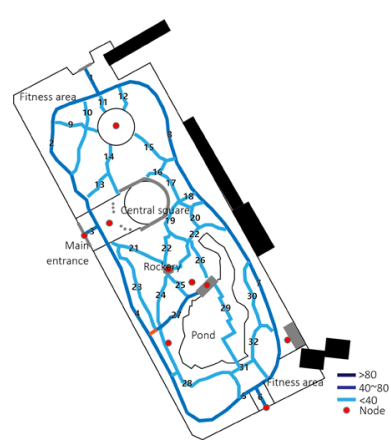

JX Park

Figure 3. Path extraction and the number the elderly in sample parks in winter. Source: Authors.

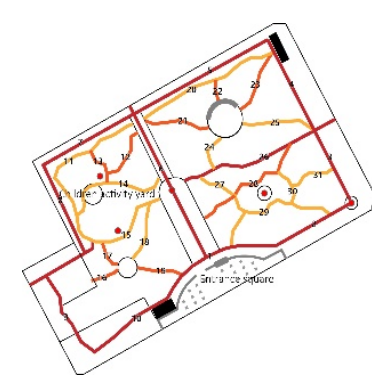

DS Park

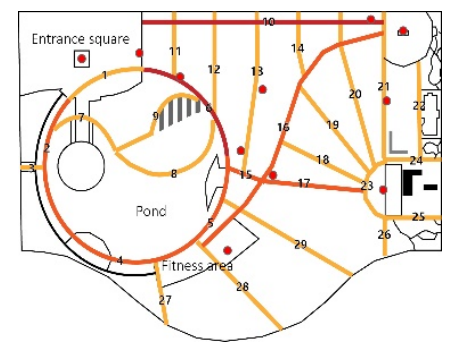

JJ Park

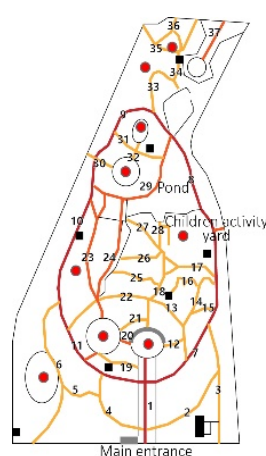

CC Park entrance

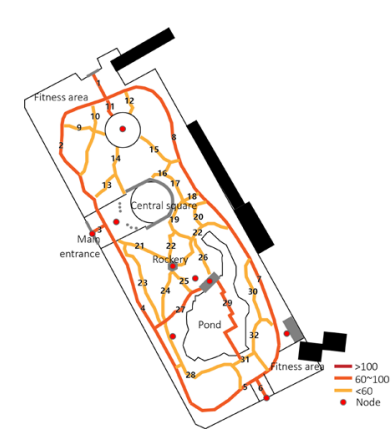

JX Park

Figure 4. Path extraction and the number of the elderly in sample parks in spring. Source: Authors.

In winter, $77.4 \%$ and $71.7 \%$ of the elderly in DS Park and JX Park respectively took more than three rounds of circular exercise on main paths. Only $62.3 \%$ of the elderly in CC Park exercised along the ring paths. The number of medium and high intensity activities accounted for $18.9 \%, 16.6 \%$ and $21.7 \%$ respectively in these three parks. In JJ Park, without obvious circulation route, $64.2 \%$ of the elderly usually exercised around water and central square, and the proportion of the elderly with MET $>3$ is $23.7 \%$. Moreover, JJ Park and CC Park had significantly more people exercising at night than during daytime.

In spring, most elderly people were still used to circular movement along the main line, and its proportion of DS Park, JX Park, CC Park and JX Park were 79\%, 76.3\%, 69.2\% and 68.7\% respectively. At the same time, the path support to the elderly with met $>3$ increased to $22.4 \%, 17.3 \%, 24.5 \%$ and $24.1 \%$ respectively. 


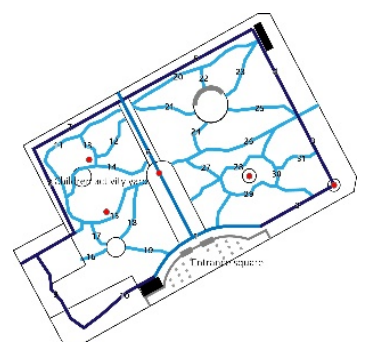

DS Park

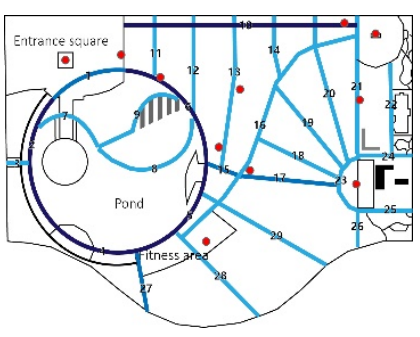

JJ Park

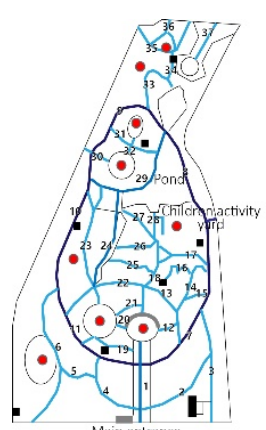

CC Park

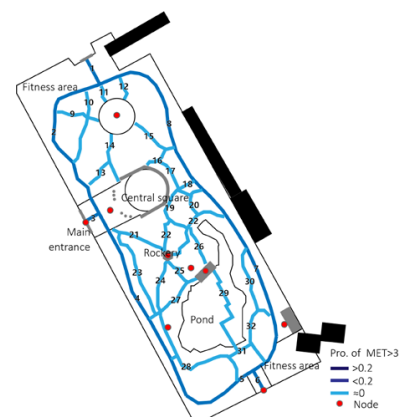

JX Park

Figure 5. The supportability of paths for medium and high intensity activities in sample parks in winter. Source: Authors.

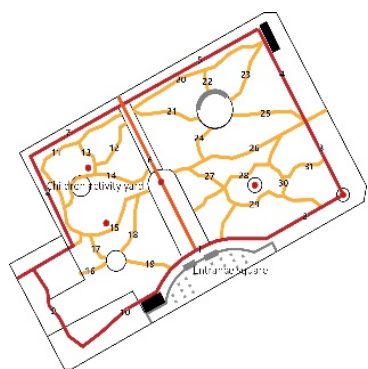

DS Park

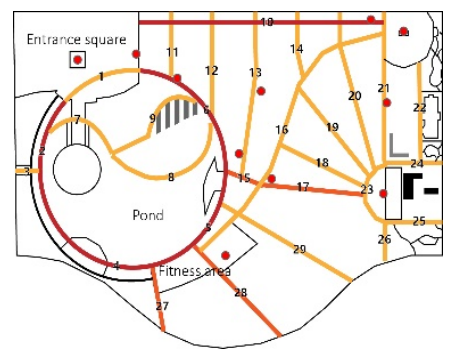

JJ Park

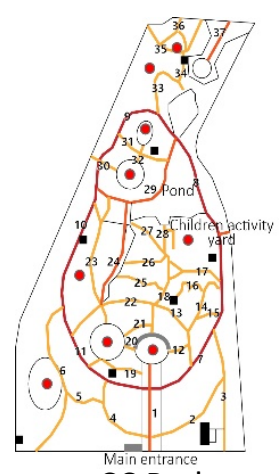

CC Park

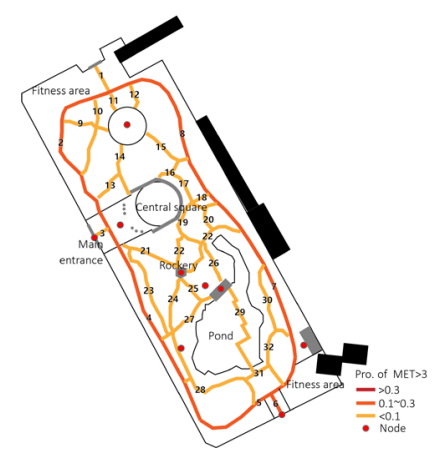

JX Park

Figure 6. The supportability of paths for medium and high intensity activities in sample parks in spring. Source: Authors.

\subsection{Perceived requirements for elderly health behaviour on pathways}

In order to better understand the internal needs of the elderly for health behaviour, we randomly selected 26 elderly people with high exercise frequency for in-depth interviews in spring and winter. Combined with the coding and translation of written materials by grounded theory, the perceived requirements for elderly health behaviour in these parks were summarized as sense of security, comfort, convenience, scenic beauty and sense of belonging (Figure 7). Among them, paths with different characteristics had different support for health behaviour of the elderly, and its needs are also different in different periods and seasons.

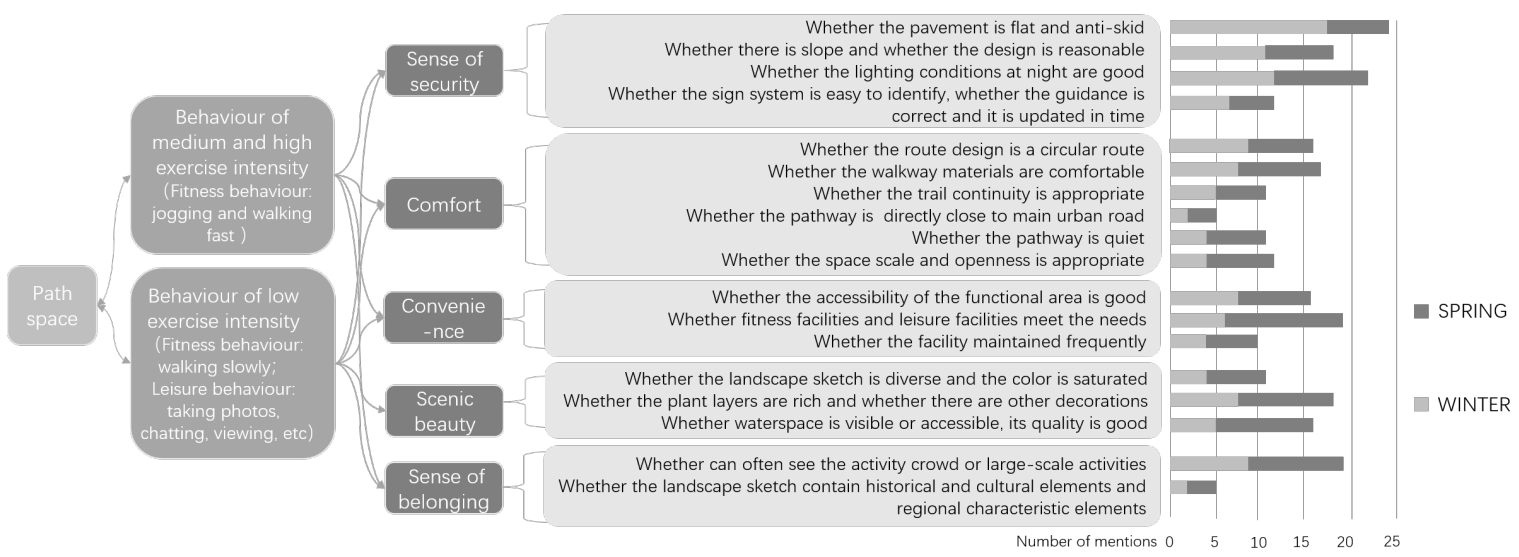

Figure 7. Perceived requirements analysis of elderly health behaviour. Source: Authors.

\subsection{Spatial feature recognition of influencing elderly health behaviour}

On account of the internal needs of the elderly for perception environment, i.e., sense of security, comfort, convenience, scenic beauty and sense of belonging, the spatial features and elements were transformed 
to identify relevant category variables and continuous variables (Table 2). We selected 13 category variables preliminarily, including a1. whether is adjacent to entrances and exits, a2. linear change, a3. whether there is slope, a4. whether the pavement is anti-skid, a5. whether the pavement is retarded, a6. whether the plant structure is rich, a7. whether there are decorations in trees, a8. whether facilities (stools, trash cans) are available, a9. whether there are signboards, a10. whether illumination is appropriate, a11. whether there are landscape sketches, a12. whether is adjacent to water, and a13. Whether the activity area is visible. Similarly, we screened 4 continuous variables, including b1. height width ratio, b2. width value, b3. length of non turning and intersection sections, and b4. green and blue vision rate. The slope and decoration cannot be further analysed in our study because there is no sufficient sample to compare, so they were removed.

Table 2. Spatial feature recognition

\begin{tabular}{|c|c|c|c|}
\hline $\begin{array}{l}\text { Internal } \\
\text { requirements }\end{array}$ & $\begin{array}{l}\text { Spatial components } \\
\text { involved }\end{array}$ & $\begin{array}{l}\text { Categorical variable } \\
\text { identification }\end{array}$ & $\begin{array}{l}\text { Continuous variable } \\
\text { identification }\end{array}$ \\
\hline Sense of security & Paving, facilities & $\begin{array}{l}\text { Whether there is a slope; whether the } \\
\text { pavement is anti-skid; whether there are } \\
\text { signboards; Whether the lighting conditions } \\
\text { at night are good }\end{array}$ & \\
\hline Comfort & Paving, plants & $\begin{array}{l}\text { Whether the pavement is retarded; linear } \\
\text { change }\end{array}$ & $\begin{array}{l}\text { Aspect ratio; width value; } \\
\text { length of sections without } \\
\text { turning or crossing; ... }\end{array}$ \\
\hline Convenience & Facilities & $\begin{array}{l}\text { Whether the pathway is close to entrances } \\
\text { and exits; whether facilities (stools, trash } \\
\text { cans) are available }\end{array}$ & \\
\hline Scenic beauty & $\begin{array}{l}\text { Plants, water } \\
\text { features, landscape } \\
\text { sketches }\end{array}$ & $\begin{array}{l}\text { Whether the plant level and collocation are } \\
\text { rich; whether there are decorations in trees; } \\
\text { whether there are sketches; whether the } \\
\text { water is visible and touchable }\end{array}$ & Green - blue vision rate; ... \\
\hline $\begin{array}{l}\text { Sense of } \\
\text { belonging }\end{array}$ & $\begin{array}{l}\text { landscape sketches, } \\
\text { functional areas }\end{array}$ & Whether the activity area is visible & \\
\hline
\end{tabular}

Furthermore, taking the above spatial characteristic elements as independent variables, the number of elderly and the proportion of the elderly with MET > 3 as dependent variables, we conducted several groups of correlation analysis to obtain the perceived preferences and significant influencing factors of the elderly. Among them, independent sample T-test method was used for category variables, Pearson correlation analysis was used for continuous variables, and the following results were obtained ( Table 3 and 4 ).

Table 3. Category variables that significantly affect elderly health behaviour on pathways

\begin{tabular}{|c|c|c|c|c|c|c|c|c|c|c|c|c|c|c|c|c|}
\hline & \multicolumn{8}{|c|}{ Proportion of the elderly with MET > 3} & \multicolumn{8}{|c|}{ Number of the elderly } \\
\hline & \multicolumn{2}{|c|}{ Winter D. } & \multicolumn{2}{|c|}{ Winter $\mathbf{N}$. } & \multicolumn{2}{|c|}{ Spring D. } & \multicolumn{2}{|c|}{ Spring N. } & \multicolumn{2}{|c|}{ Winter D. } & \multicolumn{2}{|c|}{ Winter $\mathbf{N}$. } & \multicolumn{2}{|c|}{ Spring D. } & \multicolumn{2}{|c|}{ Spring $\mathbf{N}$. } \\
\hline & $T$ & Sig. & $\mathrm{T}$ & Sig. & $\mathrm{T}$ & Sig. & $T$ & Sig. & $T$ & Sig. & $\mathrm{T}$ & Sig. & $T$ & Sig. & $T$ & Sig. \\
\hline a1 & $\begin{array}{l}-.2 \\
11\end{array}$ & .844 & $\begin{array}{l}1.4 \\
97\end{array}$ & .213 & $\begin{array}{l}.30 \\
6\end{array}$ & .776 & $\begin{array}{l}1.5 \\
44\end{array}$ & .202 & $\begin{array}{l}-.1 \\
19\end{array}$ & .912 & $\begin{array}{l}.78 \\
6\end{array}$ & .480 & $\begin{array}{l}-.6 \\
94\end{array}$ & .538 & $\begin{array}{l}.40 \\
3\end{array}$ & .710 \\
\hline $\mathrm{a} 2$ & $\begin{array}{l}1.2 \\
64\end{array}$ & .279 & $\begin{array}{l}-.2 \\
70\end{array}$ & .801 & $\begin{array}{l}1.2 \\
35\end{array}$ & .288 & $\begin{array}{l}-.4 \\
88\end{array}$ & .653 & $\begin{array}{l}1.6 \\
77\end{array}$ & .176 & $\begin{array}{l}.34 \\
8\end{array}$ & .747 & $\begin{array}{l}.73 \\
4\end{array}$ & .506 & $\begin{array}{l}.08 \\
0\end{array}$ & .941 \\
\hline a4 & $\begin{array}{l}2.8 \\
85\end{array}$ & .048 & $\begin{array}{l}.55 \\
1\end{array}$ & .612 & $\begin{array}{l}2.2 \\
30\end{array}$ & .094 & $\begin{array}{l}.35 \\
1\end{array}$ & .745 & $\begin{array}{l}2.9 \\
80\end{array}$ & .046 & $\begin{array}{l}1.3 \\
94\end{array}$ & 0.243 & $\begin{array}{l}.87 \\
7\end{array}$ & .433 & $\begin{array}{l}.45 \\
7\end{array}$ & .674 \\
\hline
\end{tabular}


Yan, T.J.; LENG, $\mathrm{H}$.

Evidence-based design of perceived pathways in cold regional parks for elderly health behaviour

\begin{tabular}{|c|c|c|c|c|c|c|c|c|c|c|c|c|c|c|c|c|}
\hline a5 & $\begin{array}{l}3.4 \\
58\end{array}$ & .028 & $\begin{array}{l}.67 \\
6\end{array}$ & .538 & $\begin{array}{l}2.8 \\
35\end{array}$ & .050 & $\begin{array}{l}.45 \\
3\end{array}$ & .675 & $\begin{array}{l}2.4 \\
04\end{array}$ & .078 & $\begin{array}{l}1.4 \\
33\end{array}$ & .229 & $\begin{array}{l}.86 \\
8\end{array}$ & .376 & $\begin{array}{l}.57 \\
7\end{array}$ & .597 \\
\hline a6 & $\begin{array}{l}.76 \\
8\end{array}$ & .488 & $\begin{array}{l}.34 \\
1\end{array}$ & .751 & $\begin{array}{l}.92 \\
0\end{array}$ & .413 & $\begin{array}{l}.27 \\
9\end{array}$ & .795 & $\begin{array}{l}.74 \\
5\end{array}$ & .502 & $\begin{array}{l}.62 \\
1\end{array}$ & .571 & $\begin{array}{l}2.8 \\
36\end{array}$ & .050 & $\begin{array}{l}.11 \\
2\end{array}$ & .916 \\
\hline a8 & $\begin{array}{l}-.6 \\
28\end{array}$ & .568 & $\begin{array}{l}.16 \\
7\end{array}$ & .876 & $\begin{array}{l}-.6 \\
34\end{array}$ & .563 & $\begin{array}{l}.40 \\
7\end{array}$ & .706 & $\begin{array}{l}-.7 \\
11\end{array}$ & .520 & $\begin{array}{l}-.2 \\
84\end{array}$ & .792 & $\begin{array}{l}-.2 \\
35\end{array}$ & .826 & $\begin{array}{l}.09 \\
0\end{array}$ & .933 \\
\hline a9 & $\begin{array}{l}.15 \\
5\end{array}$ & .885 & $\begin{array}{l}-.4 \\
18\end{array}$ & .699 & $\begin{array}{l}.30 \\
1\end{array}$ & .730 & $\begin{array}{l}-.4 \\
91\end{array}$ & .651 & $\begin{array}{l}-.1 \\
02\end{array}$ & .924 & $\begin{array}{l}-.3 \\
14\end{array}$ & .771 & $\begin{array}{l}.36 \\
1\end{array}$ & .737 & $\begin{array}{l}.02 \\
7\end{array}$ & .980 \\
\hline a10 & $\begin{array}{l}.12 \\
0\end{array}$ & .910 & $\begin{array}{l}2.8 \\
48\end{array}$ & .050 & $\begin{array}{l}.32 \\
1\end{array}$ & .761 & $\begin{array}{l}2.9 \\
48\end{array}$ & .045 & $\begin{array}{l}.22 \\
7\end{array}$ & .833 & $\begin{array}{l}2.9 \\
27\end{array}$ & .049 & $\begin{array}{l}-.5 \\
93\end{array}$ & .587 & $\begin{array}{l}2.9 \\
60\end{array}$ & .047 \\
\hline a11 & $\begin{array}{l}.48 \\
4\end{array}$ & .655 & $\begin{array}{l}.35 \\
6\end{array}$ & .741 & $\begin{array}{l}.21 \\
6\end{array}$ & .840 & $\begin{array}{l}.33 \\
6\end{array}$ & .755 & $\begin{array}{l}-.0 \\
36\end{array}$ & .973 & $\begin{array}{l}.11 \\
9\end{array}$ & .912 & $\begin{array}{l}.20 \\
7\end{array}$ & .847 & $\begin{array}{l}.17 \\
9\end{array}$ & .867 \\
\hline a12 & $\begin{array}{l}.57 \\
7\end{array}$ & .597 & $\begin{array}{l}-.7 \\
24\end{array}$ & .512 & $\begin{array}{l}.38 \\
3\end{array}$ & .723 & $\begin{array}{l}-.8 \\
34\end{array}$ & .454 & $\begin{array}{l}.40 \\
7\end{array}$ & .707 & $\begin{array}{l}-.1 \\
83\end{array}$ & .864 & $\begin{array}{l}2.8 \\
55\end{array}$ & .049 & $\begin{array}{l}.52 \\
5\end{array}$ & .630 \\
\hline a13 & $\begin{array}{l}.54 \\
9\end{array}$ & .614 & $\begin{array}{l}-.1 \\
66\end{array}$ & .876 & $\begin{array}{l}.24 \\
6\end{array}$ & .818 & $\begin{array}{l}-.1 \\
91\end{array}$ & .858 & $\begin{array}{l}2.9 \\
18\end{array}$ & .049 & $\begin{array}{l}.29 \\
0\end{array}$ & .788 & $\begin{array}{l}.14 \\
5\end{array}$ & .892 & $\begin{array}{l}.16 \\
7\end{array}$ & .880 \\
\hline
\end{tabular}

Note: D. stands for daytime, N. stands for night.

Table 3. Continuous variables that significantly affect elderly health behaviour on pathways

\begin{tabular}{|c|c|c|c|c|c|c|c|c|c|c|c|c|c|c|c|c|}
\hline & \multicolumn{8}{|c|}{ Proportion of the elderly with MET > 3} & \multicolumn{8}{|c|}{ Number of the elderly } \\
\hline & \multicolumn{2}{|c|}{ Winter D. } & \multicolumn{2}{|c|}{ Winter $\mathbf{N}$. } & \multicolumn{2}{|c|}{ Winter D. } & \multicolumn{2}{|c|}{ Winter $\mathbf{N}$. } & \multicolumn{2}{|c|}{ Winter D. } & \multicolumn{2}{|c|}{ Winter N. } & \multicolumn{2}{|c|}{ Winter D. } & \multicolumn{2}{|c|}{ Winter $\mathbf{N}$. } \\
\hline & $p$ & Sig. & $P$ & Sig. & $P$ & Sig. & $P$ & Sig. & $P$ & Sig. & $P$ & Sig. & $P$ & Sig. & $P$ & Sig. \\
\hline b1 & $\begin{array}{l}-.2 \\
95\end{array}$ & .582 & $\begin{array}{l}.20 \\
6\end{array}$ & .705 & $\begin{array}{l}-.3 \\
42\end{array}$ & .521 & $\begin{array}{l}.22 \\
5\end{array}$ & .678 & $\begin{array}{l}-.2 \\
31\end{array}$ & .670 & $\begin{array}{l}.00 \\
2\end{array}$ & .997 & $\begin{array}{l}-.870 \\
*\end{array}$ & .029 & $\begin{array}{l}-.0 \\
84\end{array}$ & .878 \\
\hline b2 & $\begin{array}{l}.15 \\
5\end{array}$ & .777 & $\begin{array}{l}.31 \\
5\end{array}$ & .556 & $\begin{array}{l}.29 \\
9\end{array}$ & .578 & $\begin{array}{l}.32 \\
3\end{array}$ & .546 & $\begin{array}{l}.08 \\
0\end{array}$ & .884 & $\begin{array}{l}.27 \\
0\end{array}$ & 616 & -.237 & .662 & $\begin{array}{l}.07 \\
2\end{array}$ & .896 \\
\hline b3 & $\begin{array}{l}.84 \\
8^{*}\end{array}$ & .039 & $\begin{array}{l}.38 \\
0\end{array}$ & .472 & $\begin{array}{l}.89 \\
5^{*}\end{array}$ & .020 & $\begin{array}{l}.35 \\
5\end{array}$ & .504 & $\begin{array}{l}.53 \\
2\end{array}$ & .293 & $\begin{array}{l}.63 \\
6\end{array}$ & .189 & .287 & .594 & $\begin{array}{l}.38 \\
2\end{array}$ & .470 \\
\hline b4 & -- & -- & -- & -- & $\begin{array}{l}.20 \\
9\end{array}$ & .701 & $\begin{array}{l}-.1 \\
82\end{array}$ & .739 & - & -- & -- & -- & $.883^{*}$ & .024 & $\begin{array}{l}.08 \\
3\end{array}$ & .879 \\
\hline
\end{tabular}

Note: D. stands for daytime, N. stands for night; *P $<0.05, * * \mathrm{P}<0.01, * * * \mathrm{P}<0.001$.

\subsection{Perceived pathways evaluation of elderly health behaviour}

In view of the above significance analysis of the spatial characteristics of elderly health behaviour, and combined with their internal needs, we selected specific indicators of each dimension. These selected indicators were used for scoring evaluation, and the weight was adjusted according to different walking types (Table 5).

Table 5. Perception evaluation of pathways

\begin{tabular}{l|l|l}
\hline \multicolumn{1}{c|}{ Evaluation dimension } & \multicolumn{1}{|c}{ Selection of main indicators } & \multicolumn{1}{c}{ Scoring } \\
\hline Sense of security & $\begin{array}{l}\text { Anti-slip degree, illuminance of } \\
\text { lighting facilities }\end{array}$ & $\begin{array}{l}\text { Medium and high intensity exercise: high; low- } \\
\text { intensity exercise: high }\end{array}$ \\
\hline Comfort & Retardation and continuity & $\begin{array}{l}\text { Medium and high intensity exercise: high; low- } \\
\text { intensity exercise: low }\end{array}$ \\
\hline
\end{tabular}




\begin{tabular}{l|l|l}
\hline Convenience & Facility completeness & $\begin{array}{l}\text { Medium and high intensity exercise: low; low- } \\
\text { intensity exercise: low }\end{array}$ \\
\hline Scenic beauty & $\begin{array}{l}\text { Green and blue visual rate, Plant } \\
\text { richness }\end{array}$ & $\begin{array}{l}\text { Medium and high intensity exercise: low; low- } \\
\text { intensity exercise: high }\end{array}$ \\
\hline Sense of belonging & Activity site visibility & $\begin{array}{l}\text { Medium and high intensity exercise: low; low- } \\
\text { intensity exercise: high }\end{array}$ \\
\hline
\end{tabular}

The evaluation criteria of relevant indicators are as follows:

Retardation and anti-slip degree: The current situation of these parks shows that the pavement materials mainly include plastic, concrete, wooden plank, stone and gravel. Considering the safety and comfort of sports, plastic is rated 5 points, concrete 4 points, wooden plank road 3 points, stone 2 points and gravel 1 point.

Illuminance of lighting facilities: Pathways on site are mainly illuminated by vertical street lamps. According to the lighting standards and actual conditions, the paths with illuminance $>21 \mathrm{x}$ and other auxiliary lighting are rated as 5 points, 15-21lx as 4 points, $10-15$ as 3 points, 5-10lx as 2 points, and < 5lx without other auxiliary lighting as 1 point.

Continuity: The survey shows that the faster people walk, the more they prefer continuous paths. The long section without turning and crossing on site is about $200 \mathrm{~m}$. Therefore, taking $200 \mathrm{~m}$ as the cut-off point and considering the current situation ,the scoring rules are: 5 points for $>200 \mathrm{~m}, 4$ points for $100 \sim 199 \mathrm{~m}, 3$ points for $50 \sim 99 \mathrm{~m}, 2$ points for $20 \sim 49 \mathrm{~m}$ and 1 point for $<19 \mathrm{~m}$.

Blue-green visual rate: We used greenrate to analyze the pictures of the pathways we took. According to the analysis results, the average blue-green visual rate is $25 \%$, and the maximum and minimum values are $49 \%$ and $12 \%$. Therefore, when the value is $>40 \%$, give 5 points, $30-40 \% 4$ points, $30-20 \% 3$ points, $10-20 \%$ 2 points and $<10 \% 1$ point.

Facility completeness: If all facilities meet the use needs and are updated and maintained in time, 5 points can be given, 4 points can be given if they meet the use needs, 3 points can be given if they meet the basic use needs, 2 points for insufficient facilities and occasional maintenance, and 1 point for obvious insufficient facilities and no renewal and maintenance.

Richness of plant level and visibility of activity site: 5 points can be given if the sight is transparent and the structure level is rich, such as "arbor-shrub-grass" structure; clear sight and relatively rich levels, such as "shrub-grass", rate 4 points; give 3 points for medium visibility, such as "arbor-grass"; poor visibility, such as "tall trees - low trees", 2 points can be given; unable to see the activity area, give 1 point.

From these foundations,-the significant influencing factors can be scored twice, and the evaluation results of these sample parks can be converted. These results can be used: for one thing, the obtained fivedimensional score map can not only compare different parks horizontally, but also select the priority of spatial optimization at the individual level of the park (Figure 8, left); for another, integrating the five dimensions of each park, we can evaluate the ability of paths in different parks to support healthy behaviors with different intensities, and optimize those paths (Figure 8 , right).

Comparing the five-dimensional evaluation map of each sample park, it can be seen that: DS Park has high scores in the dimensions of sense of belonging and convenience; JJ Park has high scores in sense of security and comfort; CC Park has high scores in the dimensions of scenic beauty, security and comfort; JX Park is outstanding in terms of scenic beauty. In terms of the support of sample parks for different intensity health behaviours, JJ Park has stronger support for medium and high intensity sports as a whole, and CC Park has stronger support for different intensity sports, with little difference. JX Park may not have high support for both because of its scale limit. 


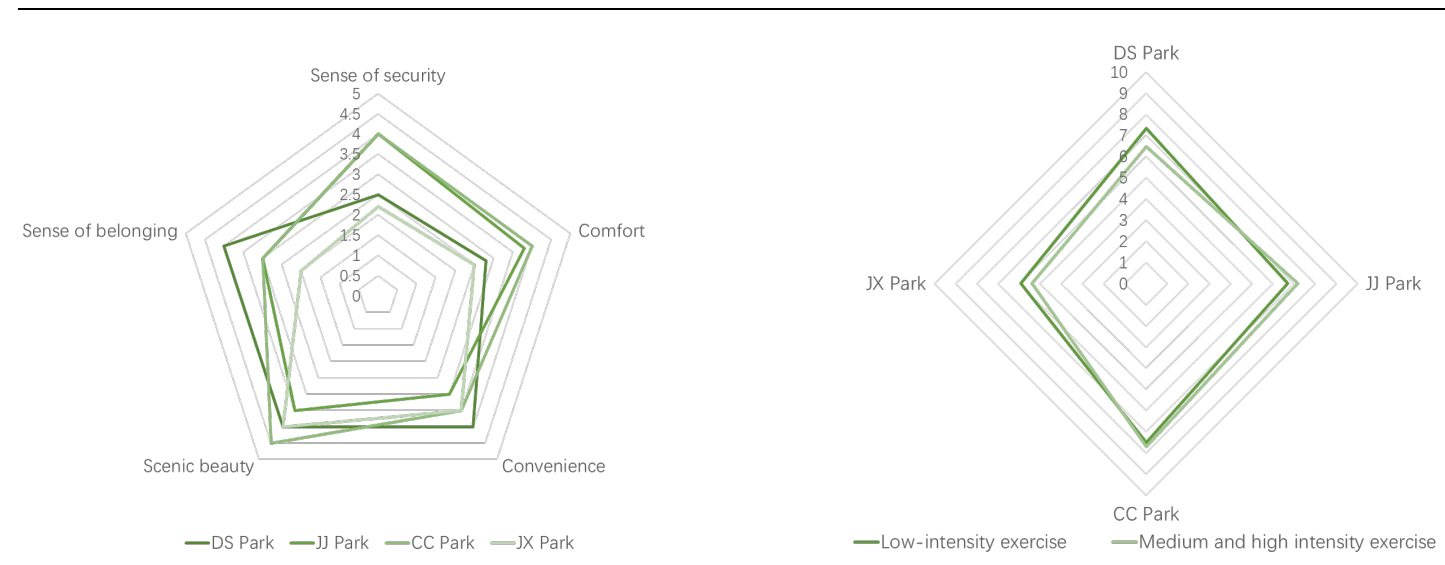

Figure 8. Five dimensional evaluation results of sample parks (left); Supporting evaluation results of sample parks for different intensity exercise (right). Source: Authors.

\section{Discussion}

\subsection{Attention of the elderly to spatial characteristics under different exercise intensity}

When the elderly carry out medium and high intensity health behaviour, they pay more attention to the characteristic elements of the pathway itself. And they do not have high requirements for the landscape on both sides of the path, and the effect of each factor varies with different behaviours. Jogging and other fast-speed activities have high requirements for the continuity, retardation and anti-skid degree of the path. The main reasons are as follows: firstly, jogging mostly occurs on the main pathways in these parks with strong continuity. Because its rhythm is stronger than other types of behaviour, if there are too many turns and more intersections, the movement rhythm will be affected, and it is easy to be injured due to untimely pace control. Secondly, joggers prefer plastic pavement with greater retardation. Because of its good shock absorption effect, it can reduce the damage to the joints caused by fast-speed movement. Thirdly, because of its fast speed and weak visual perception, the completeness of facilities, the beauty of landscape and the sense of spatial belonging are not the leading factors affecting the choice of pathways.

For low-intensity exercise, due to the slow speed, the elderly have higher demand for the scenic beauty, turning richness and interest of the path space, and their leisure willingness is also enhanced. Therefore, they have higher requirements for scenic beauty and facility completeness.

\subsection{The spatial characteristics that significantly affect elderly health behaviour in different seasons and different times of a day}

Through the comparison of observation results and interviews, it is found that: in winter, most elderly people exercise with low-intensity for the purpose of fitness. In addition to the overall moving line design, the spatial elements that significantly affect the exercise intensity of the elderly in the daytime are whether the pavement is anti-skid, retarded and the length with no turning and no disturbing section. The spatial elements that significantly affect the preference of elderly health behaviour are whether the pavement is anti-skid and whether the activity area is visible. First of all, the elderly are most concerned about the safety of space. They just want to assist in fitness, and will not have too high requirements for exercise intensity. Secondly, the elderly prefer areas where people often gather. The interaction with people can promote their fitness behaviour and leisure behaviour. Furthermore, although some elements are not significant in the statistical results, combined with the interview, it is found that they prefer the semi open space with regular evergreen plants on both sides. On the one hand, the elderly believe that there are trees around the path during the day, which can create a safe atmosphere. On the other hand, these plants can play a guiding role to a certain extent. Similar to the trees along the path in JX Park, decorating them of fake 
flowers and leaves with different colours can improve their pleasure during exercise. In terms of facilities, the design of landscape sketches will attract some elderly people to stay. Reasonable allocation of signboards with obvious instructions will also play a role in promoting to a certain extent. The setting of seat stools and garbage cans have no effect on healthy behaviour. Additionally, for the path space at night, appropriate lighting design and flat pavement are the most important factors.

In spring, the purpose of fitness and recreation of the elderly has been enhanced, and the proportion of medium and high-intensity sports and the number of the elderly have increased as a whole. The results show that: firstly, the spatial characteristic factors that significantly affect the daytime exercise intensity of the elderly on the pathways are whether the pavement is retarded and the length of the section without turning and intersection. The reason may be that, on the one side, no accumulated snow in spring has an impact on the paving, and the material performance of the paving itself is highlighted. Moreover, the demand for fitness for the elderly in spring is stronger. Materials such as plastic runway can weaken the damage to joints during rapid exercise and improve the continuity and comfort of exercise. On the other side, jogging and fast walking people pay more attention to the health benefits brought by exercise itself, and are more inclined to individual undisturbed fitness behaviour. Secondly, the spatial characteristics that significantly affect their spatial preference are whether the plant structure is rich, whether it is adjacent to the water body, aspect ratio and blue-green visual rate. In spring, the path spaces carry various types of elderly health behaviours, mostly low-intensity fitness behaviours dominated by walking, accompanied by leisure behaviours such as recreation, photography and chat. Therefore, they pay most attention to the beauty of the scenery around the pathways. Water can improve the microclimate of local space, and the calm and open water surface can restore and improve their emotional state, the elderly prefer to move in the path space of adjacent waterscape hence. Similarly, path spaces with colourful flowers and leaves will attract more elderly people to take photos and enjoy the scenery, and indirectly lead to more social behaviour. Aspect ratio and blue-green visual rate are the most direct factors affecting the spatial perception of the elderly. It is found that the number of activities is the largest when the aspect ratio is between $2.0 \sim 2.5$. When the blue-green visual rate is greater than $30 \%$, the elderly feel better about space. Due to the limited sample size, no repressed spatial feeling caused by too large green visual rate is found. Additionally, although the facility elements do not show a significant impact in statistics, their reasonable allocation and maintenance will also improve the spatial perception of elderly health behaviour. At last, lighting conditions are the most important factor for the activity intensity and number of people at night in spring.

\subsection{Optimization strategy of pathways based on evaluation results}

\subsubsection{Overall configuration optimization}

At first, on the whole, the use feeling of the path spaces can be ameliorated by improving the moving line design and functional configuration. In particular, JJ Park can strengthen the circular route guidance of the main path. Other path spaces should also be divided into areas with different exercise intensity, namely aerobic jogging area and high-energy walking area. At the meanwhile, it is necessary to increase the sign prompt system and night running navigation system, and cooperate with planting with different characteristics (Figure 9).

\subsubsection{Detail design optimization}


The detailed design can be optimized by decomposing the constituent elements of the path space, i.e. paving, plants and water, facilities and landscape sketches, so as to meet the supporting needs of various spaces.

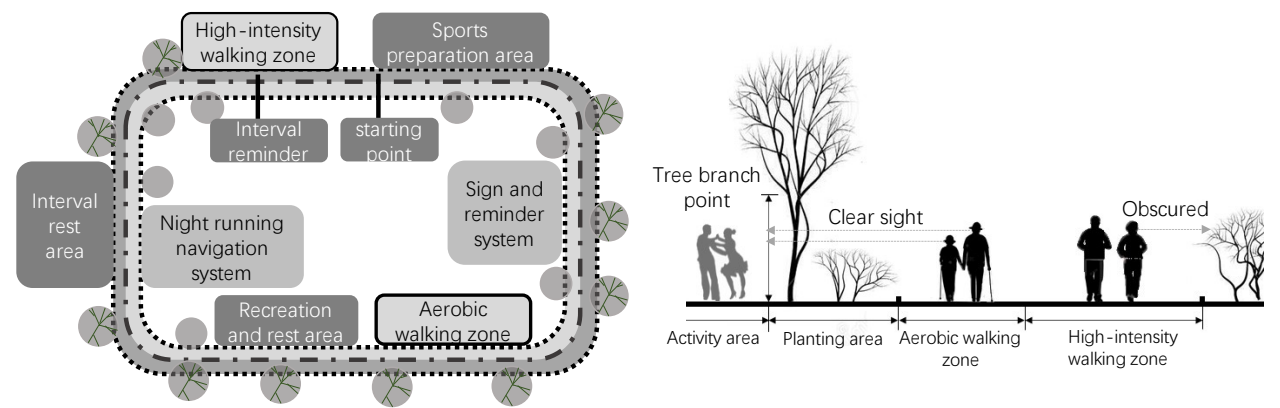

Figure 9. Schematic diagram of path space intensity zoning (left); Schematic diagram of path space cross section(right). Source: Authors.

1) Paving. The paving material can be selected according to different exercise intensity. Plastic can be used in high-energy walking area to improve the comfort of walking. The slow walking area can be made of anti-skid materials such as permeable bricks, or some areas can be combined with pebbles to change the splicing mode and texture of the pattern, so as to improve the safety, increase the interest and achieve the effect of massage. It is also suggested to mark "starting point, 50m interval" and other signs on the pavement near the entrance to facilitate the elderly group to calculate their exercise.

2) Plants and water. The combination of "trees with higher branching points + shrubs " can be selected for the plants between the walking area and the activity area to increase the sense of spatial permeability and promote the interaction of different spatial activity groups. Plants that can block the line of sight should be planted next to the walking area, so as to form a clear guidance and improve the continuity of high-intensity exercise (Figure 9). In terms of plant configuration, flowering plants should be given priority. In combination with seasonal changes, plants with unique seasonal aspect and health care plants can be selected. Medical research has found that breathing in the face of pine trees can reduce the incidence of cardiovascular diseases by $20 \%$ (Leng, H.,etc..2021), hence it can increase the planting of pine trees. When possible, the visibility of water body can also be increased in the path space. Artificial waterscape and simulated waterscape can also improve their spatial perception. It is worth mentioning that plant barriers are supposed to be appropriately added between pathways in park directly connected to urban roads. Evergreen trees such as pine, cypress and fir can be selected to reduce the harm of automobile exhaust pollution and improve the comfort and safety of the site(Yang J.H. ,etc..2017).

3) Facilities and landscape sketches. Antiseptic timber that can adapt to climate change can be considered in the selection of leisure facilities to improve the comfort of intermittent sports. In full consideration of the falling of ice and snow in winter and shading in spring, leisure facilities, goods placement facilities and lighting facilities can be appropriately added. Lighting facilities can be set in combination with ground lamps or lamp strips, and the illuminance and colour temperature of light sources can be adjusted reasonably. According to relevant research conclusions, it is best to adjust the illuminance value to about $42 \mathrm{~lx}$. When the illuminance of spatial light source is low, the colour temperature can be adjusted to 500K to compensate the visual feeling of space (Ma, H., etc..2019). Further, it is very necessary to add night navigation system and sign prompt system, especially in parks with large scale and unclear route like CC Park. Considering the eyesight of the elderly, the font of the identification system ought to be increased, its colour ought to be coordinated, and the day and night brightness conversion and real-time ought to be ensured. Its content is supposed to meet the needs of science popularization and prompt. Landscape sketches can combine the characteristics of ice and snow, increase the colour expression and regional culture of structures, and appropriately add colourful decoration on trees to improve the atmosphere of the park and improve the interest and attachment of the site landscape. 


\subsubsection{Management and maintenance optimization}

Improving the management and maintenance of the pathways in parks can be implemented from three aspects: seasonal resource transformation, environmental quality maintenance and timely renewal of facilities. Firstly, it is suggested to make full use of ice and snow resources in winter and tourism resources in spring, and carry out sports and competitive games for the elderly by relying on street or community organizations. Secondly, the maintenance of environmental quality mainly includes timely cleaning up snow, fallen leaves and garbage to keep the fitness environment clean and tidy. Thirdly, old fitness facilities and identification systems should be repaired and updated in time to ensure their safety, comfort and convenience.

\section{Conclusion}

Based on above discussion and conclusion, these optimization strategies can be extended to similar parks in order to better meet the use needs of the elderly. Last but not least, more empirical studies are needed in the future to effectively improve the health effect of the park on the elderly and improve the overall health level of the elderly under the special climate background.

\section{Acknowledgements}

This research financially supported by National Natural Science Foundation of China (No.51978192).

\section{References}

Tinsley, H.E.A., Tinsley, D.J., Croskeys, C.E.. (2002) 'Park Usage, Social Milieu, and Psychosocial Benefits of Park Use Reported by Older Urban Park Users from Four Ethnic Groups', Leisure Sciences, 24(2), p199-218.

Danya, K., \& Jin, J.. (2018) 'Does happiness data say urban parks are worth it?', Landscape and Urban Planning, 178, p1-11.

Kemperman, A.D.A.M., \& Timmermans, H.J.P.. (2006) 'Heterogeneity in urban park use of aging visitors: a latent class analysis', Leisure Sciences, 28(1), p57-71.

Loukaitou-sideris, A., Levy-storms, L., CHEN, L., et al.. (2017) 'Parks for an aging population: needs and preferences of low-income seniors in los angeles', Journal of the American Planning Association, 82(3), p1-16.

Lee, I. , Shiroma, E. J. , Lobelo, F. , et al.. (2012) 'Effect of physical inactivity on major non-communicable diseases worldwide: an analysis of burden of disease and life expectancy', Lancet, 380(9838), p219-229.

Tucker, P. , \& Gilliland, J.. (2007) 'The effect of season and weather on physical activity: a systematic review', Public Health, 121(12), p909-922.

Leng, H. (2009) Study on livability of urban environment in cold areas. Beijing: China Construction Industry Press.

Shores, K. A. , \& West, S. T.. (2008) 'The relationship between built park environments and physical activity in four park locations', J Public Health Manag Pract, 14(3), e9.

Chungdo, J. J. , Davis, E. , Lee, S. , et al.. (2011) 'An observational study of physical activity in parks in asian and pacific islander communities in urban honolulu, hawaii, 2009.', Preventing Chronic Disease, 8(5), A107. 
Tester, J. , \& Baker, R.. (2009) 'Making the playfields even: evaluating the impact of an environmental intervention on park use and physical activity', Preventive Medicine, 48(4), p316-320.

Hino, A. , Reis, R. S. , Ribeiro, I. C. , et al.. (2010) 'Using observational methods to evaluate public open spaces and physical activity in brazil', Journal of Physical Activity \& Health, 7 Suppl 2(4), S146.

Child, S. T. , Mckenzie, T.L., Arredondo, E.M., et al.. (2014) 'Associations between park facilities, user demographics, and physical activity levels at san diego county parks', Journal of Park \& Recreation Administration, 32(4), p68-81.

Han, B. , D Cohen, \& Mckenzie, T.L.. (2013) 'Quantifying the contribution of neighborhood parks to physical activity', Preventive Medicine, 57(5), p483-487.

Zhai, Y., Li, D., Wu, C., \& Wu, H.. (2020) 'Urban park facility use and intensity of seniors' physical activity an examination combining accelerometer and GPS tracking', Landscape and Urban Planning, 205: 103950.

Yang J.H., Pang Z.R., Huang H.D., et al.. (2017) 'Adsorption of Different Evergreen Plants to PM2.5 in Winter', Journal of Tianjin Agricultural University ,24(04),p19-22. doi:CNKI:SUN:TJXY.0.2017-04005 .

Leng, H., Li, S.Y., Zhao, H.M..(2021) 'Research on Urban Park Planning in Cold Regions to Promote Fitness Behavior for Cardiovascular Health', Landscape Architecture, 28(03),p69-74. doi:10.14085/j.fjyl. 2021.03.0069.06.

Ma, H., Zhu, K., Li, J. W., Yang, B..(2019) 'A Study on the Improvement of Neighborhood Pedestrian Space for Senior People with Visual Degradation', Planners, (14),p12-17. doi:CNKI:SUN:GHSI.0.2019-14002 . 